\title{
Drive System for the TEXT Upgrade Generators
}

\author{
By: \\ J.D. Herbst \\ J.W. Jagger \\ D.L. Foster \\ D.R. Terry
}

IEEE 14th Symposium on Fusion Engineering September 30 to October 4, 1991

PN - 214

Center for Electromechanics

The University of Texas at Austin BRC, Mail Code 77000

Austin, TX 78712

(512) $471-4496$ 


\title{
DRIVE SYSTEM FOR THE TEXT UPGRADE GENERATORS
}

\author{
John D. Herbsh, James W. Jagger, Debra L. Foster, David R. Terry \\ Fusion Research Center \\ University of Texs \\ Austin, Texas 78712
}

Absiracs: The 18.75 MVA generators for the Texas Experimental Tokamak (TEXT) Upgrade will each be driven by a $298 \mathrm{~kW}$ electric motor. The motor will be coupled to the generator by a hydraulic transmission system. This paper describes the drive system, and discusses why it was chosen. Also included are a description of the computer simulation used to predict the drive system performance and the simulation results.

\section{Introduction}

The Texas Experimental Tokamak (TEXT) reactor project is currently undergoing a significant system upgrade which includes the installation of two 18.75 MVA generators to provide additional pulsed power capability for the diverror and verical field power supplies and electron cyclotron heating (ECH) experiments[1]. The generators were constructed in 1928 and were originally operated by Gulf States Utilities as part of the utility grid in Baton Rouge, Louisiana. The generators have been modified for a pulsed power duty cycle and equipped with updated hydrodynamic bearings and are currently being installed in the basement of the Engineering Science building on the University of Texas main campus.

In the TEXT installation, the generators will be motored to $3600 \mathrm{rpm}$, inerrially storing approximately $46 \mathrm{MJ}$ of energy. During discharge, this energy is extracted from the generator at a peak power of $10 \mathrm{MW}$, with a pulse duration of approximately $600 \mathrm{~ms}$. Generator field excitation and the discharge pulse decelerate the rotor ro approximately $3300 \mathrm{rpm}$, and the motoring system then reaccelerates the generators for the next discharge pulse. In addicion, the motoring system provides power for ECH conditioning and low speed generator warm up cycles.

The design of the motoring system for the generators was driven by several factors, including the desired discharge repetition rate, the dynamics of the rotor/stator system, the mechanical and electromagnetic losses in the generators, and the inerria of the generator rotor. The design was constrained by cost, the power and room available at the sire, and the need for a drive system which would not introduce disturbances to the utility power grid. It was also desired that the system provide for a safe shutdown in the event of component failure or site power outages.

Existing facilities and electric utilities in the Engineering Science building defined the location and limited the power available to motor each of the two generators to $298 \mathrm{~kW}$. The relatively low power available, coupled with the large rotor ineria and long motoring times, dictated the need for a highly efficient, variable speed transmission system, capable of providing high drive torques throughout the entire generator speed range. Altemative electric drives were considered, but were rejected due to high cost, unacceptable line voltage disturbances, and the need for complex control systems.[2] A closed loop hydrostatic transmission system was finally selected based on high efficiency, low initial staring load, the ability to provide torque over a continuously variable speed range, and the flexibility of component location at the site.

\section{System and Component Descriprion}

A closed loop hydrostaric uansmission system utilizing variable displacement axial piston equipment was selected for this application. The variable displacement pump allows the electric motor to start under virtually no load condition and also provides efficient generation of high torque at very low system speeds and power levels, which is critical in an application with high rotor inerria. Also, systems of this type can operate at pressures up to $41.38 \times 10^{3} \mathrm{kPa}$, minimizing the flowrate and associated flow losses required for a given power transmission level. Figure 1 shows a simplified schematic of the system in the nompal motoring configuration.

Prime power for the hydraulic systems is provided by Marathon Electric Model PO-FS-038334, 298 kW, 460 V, three phase induction morass operating at 1780 full load $\mathrm{pm}$. The elecric motors are driven through Safronics Model E26-360-460 thyristor controlled soft starters to minimize insush currents associated with motor start-up.

The main system pumps are Rexroth Model AA4V250EL hydrostatic transmission pumps designed specifically for operation in closed circuit applications. This unit is a swashplate design, variable volume, axial piston type, with a maximum displacement of 0.250 liters per revolution and a maximum operating pressure of $44.83 \times 10^{3} \mathrm{kPa}$. The pump includes an intemal charge pump and charge pressure relief valve, two combination high pressure relief and make-up check valves, and s properionat elecuric control module. The output flowrate of the pump is variable from 0 to $100 \%$, proporional to an electric control current in the range of 200 to $600 \mathrm{~mA}$, supplied to the displacement control solenoids. The solenoids apply force to a spool valve which controls the flow of oil into or out of the control cylinder to vary the swashplate angle and piston stroke. A mechanical feedback system connected to the control piston maintains the pump output for any given current within the control range. The pump also includes a pressure compensation system, which will de-stroke the pump and reduce system flowrate as required to limit the system pressure 10 a set value. The pressure compensation system operates independendy of the electrical control system. An exiemal charge pump driven from an auxiliary power supply has been included to protect the system in the event of loss of site power.

The Rexroth Model AA6VM200EL hydraulic motor is a bent axis, variable volume, axial piston type, with a spherical control plate for high volumetric efficiencies at high pressure. The displacement of the motor is variable from 0.0412 to 0.200 liters pes revolution, with a maximum continuous operating pressure of 40.00 $\times 10^{3} \mathrm{kPa}$. The displacement of the motor is proportional to an electric current in the range of $20010600 \mathrm{~mA}$. The motor is biased toward maximum displacement, with volume decreasing (and speed increasing for a given flow) with an increase in the control current A mechanical stop limits the minimum displacement to prevent exceeding the maximum output speed of the moros. 


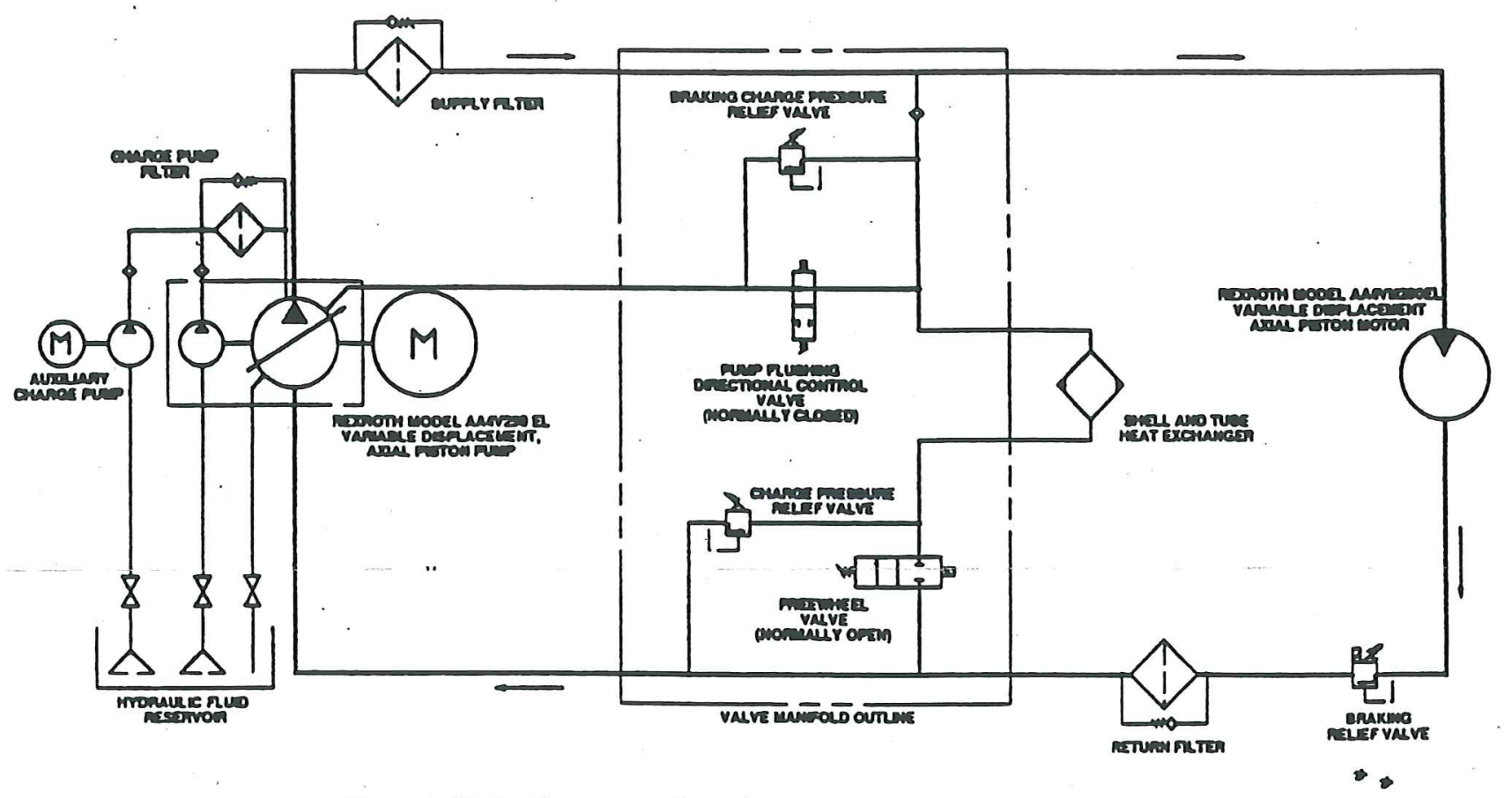

Figure 1. Hydraulic system schematic -- normal motoring configuration

The hydraulic system also includes a valve manifold containing a solenoid controlled directional contol "freewheel" valve, two pressure relief valves and connections to and from the main system heat exchanger. The valve manifold allows for an extremely compact installation and minimizes the number of hydraulic connections. The system also includes a solenoid controlled. $34.48 \times 10^{3} \mathrm{kPa}$ braking selief valve located immediately downstream from the hydraulic motor.

The control system for the generator motoring system will be integrated into an existing control system used to coordinate experiments on TEXT. Provisions for both local and remote operation will be provided. In addition to actively monitoring critical operating parameters, the control system will provide inputs to amplifier cards which generate the control currents required to regulate the hydraulic purnp and motor displacements. The control systern will also receive switch inpurs monitoring reservoir level and temperature and the condition of the fluid filters in the system.

\section{Operation}

The hydraulic system has two distinct operating modes: normal motoring and generator rotor braking. The system is designed to default safely to the sotor braking mode in the event of loss of control signals, component failure, or loss of site power. Figure 1 shows a simplified schematic of the hydraulic system in the normal motoring configuration. In this configuration, the frewheel valve solenoid is energized, closing the valve and blocking the path between the two main legs of the transmission. The braking relief valve solenoid is energized, opening the valve and providing a low pressure drop path through the valve.

During initial star-up, the pump is at zero displacement to minimize electric motor loading. Initially; the control current to the hydraulic motor is at minimum, placing the motor in the maximum displacement position. To begin motoring, the control current to the hydraulic pump is ramped up, increasing the displacement of the pump and starting oil flow through the loop. At this point, the system is operating in a constant torque mode, with output horsepower increasing linearly with hydraulic motor speed. If necessary, the integral pressure compensation system will override the control cursent setring and limit the pump output flow to a value consistent with the generator speed. Oil flows from the pump. passing through a $10 \mu \mathrm{m}$ high pressure filter and the valve manifold to the hydraulic motor. After passing through the motor, the oil passes through the braking relief valve and is filtered again before flowing through the valve manifold and renuming to the inlet side of the main pump. A small volume of hot oil is stripped from the main loop through a relief valve located in the valve manifold, passes through the system heat exchanger and the main pump case, and is then returned to the reservoir. The integral charge pump pulls cooled oil from the reservoir to replace the oil suripped from the main loop for cooling.

When the pump reaches maximum displacement and flowrate, the control cursent to the hydraulic motor is slowly increased, reducing motor displacement and further increasing speed. The system is now operating in a constant horsepower mode, with motor output torque dropping in proporion to the reduction in motor displacement. The motor displacement is reduced until the desired generator speed is reached. At this poinh the motoring system pressure will drop to provide only enough torque to overcome the generator friction and windage losses and maintain the desired speed.

During the field excitation and generator discharge sequence. the rotor speed is reduced to approximately $3300 \mathrm{spm}$. The displacement of the hydraulic motor remains unchanged, and the pressure compensation system reduces the displacement and flowrate of the main pump to match the system requirements at the reduced generator speed. The pressure compensation system allows the pump displacement to increase as required to retum the pump to maximum flowrate, maintaining full motoring pressure and torque while following the speed curve of the reaccelerating rotor. Once the generator returns to the desired set speed, the discharge sequence can be repeared. 


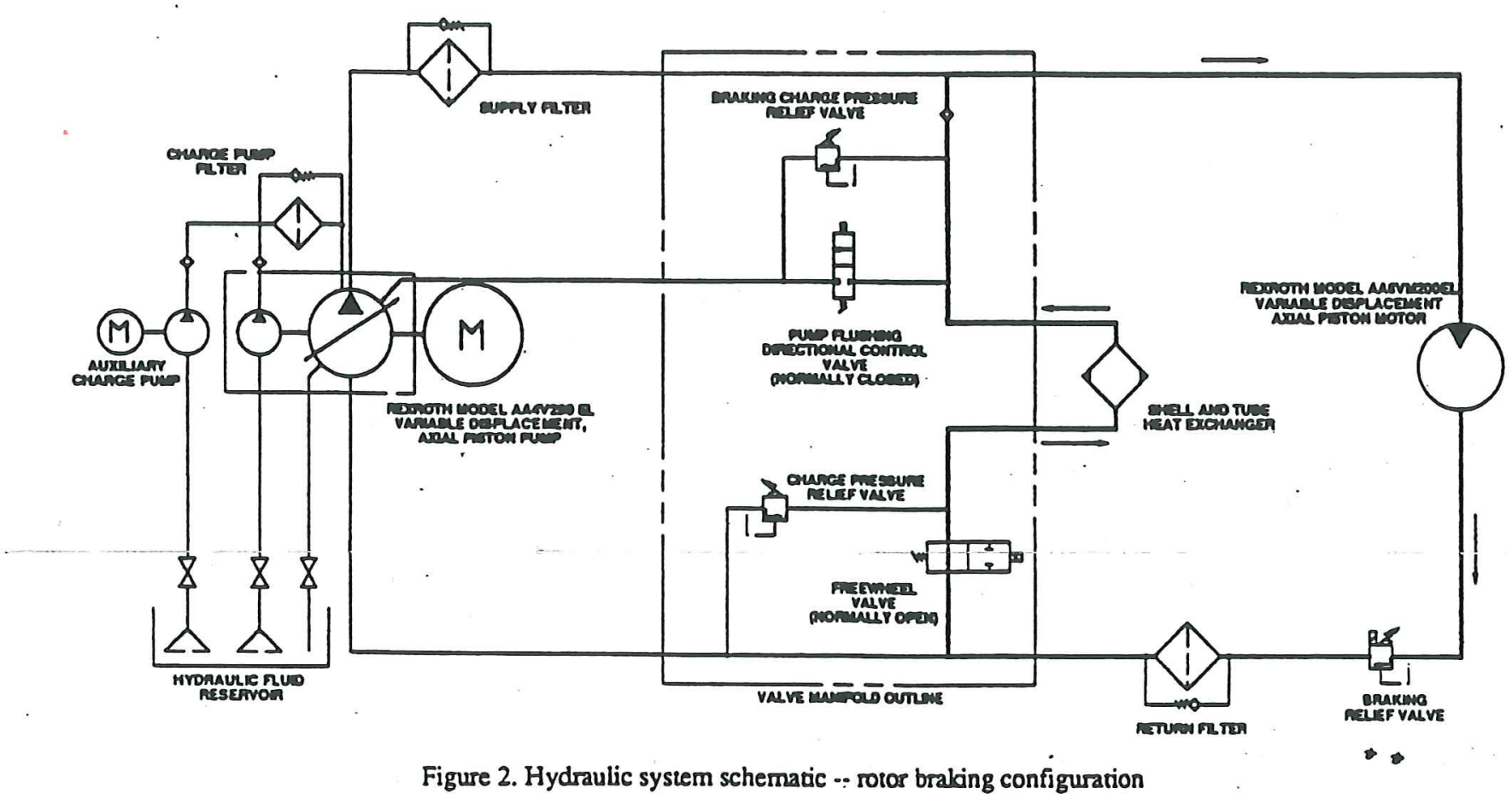

Figure 2. Hydraulic system schematic -. rolos bralang configuration

The motoring system also includes provisions for applying a braking torque to the rotor in the event of electric brake system . failure. The electric braking system is described in more detail elsewhere.[1] This is also the default mode in cases of component failure or loss of control connections. Figure 2 shows a simplified schematic of the system in the bralaing configuration.

In the braking mode, the braking valve solenoid is deenergized, allowing the valve to close and creating a high pressure drop across the valve. At the same time, the freewheel valve solenoid is de-energized, opening a flow path through the system heat exchanger and back to the inlet of the hydraulic motor. During braling, the control current to the hydraulic pump is rapidly reduced to minimum, forcing the oil leaving the hydraulic motor to pass through the freewheel valve. This increases the flowrate of oil through the heat exchanger and allows removal of the additional heat generated by the extraction of energy from the generator sotor during hydraulic braking. As the generator speed decreases, the control current to the hydraulic motor is reduced to minimum, increasing the motor displacement and maintaining the maximum flowrate across the braking relief valve.

\section{Simulation}

A computer simulation of the proposed generator motoring system was developed as an aid to component selection and to provide predictions of system performance and re-motoring times. Table 1 presents the parameters used in a typical simulation run.

The simulation incorporates the efficiencies and performance of the hydraulic components along with rotor windage, frictional losses in the hydrodynamic bearings, electromagnetic losses in the generator, field excitation power, and the energy extracted during the discharge pulse. The simulation ourpui provides data on system power input and losses, as well as a time history of rotor speed. The FORTRAN simulation is interactive, allowing the operator to input the length and power of the discharge pulse, the source of field excitation power, scale factors for generator intemal losses, and peak generator speed before discharge.
Table 1. Typical motoring system parameters

\begin{tabular}{|c|c|c|}
\hline Simulation Parameter & Value & Units \\
\hline Rotor Maximum Speed & 3600 & $\mathrm{rpm}$ \\
\hline Rotor Ineria & 658 & $\mathrm{~kg}-\mathrm{m}^{2}$ \\
\hline Electric Motor Power & 298.4 & $\mathrm{~kW}$ \\
\hline Eectric Motor Efficiency & 95.8 & $\%$ \\
\hline Windage Losses (3600 rpm) & 94.7 & $\mathrm{~kW}$ \\
\hline Bearing Losses (3600 rpm) & 32.6 & $\mathrm{~kW}$ \\
\hline Exciter Brush Losses (3600 rpm) & 7.8 & $\mathrm{~kW}$ \\
\hline Generator Losses @ Full Excitation & 70.1 & $\mathrm{~kW}$ \\
\hline Generator Losses During Discharge & 118.6 & $\mathrm{~kW}$ \\
\hline Generator Discharge Power & 10 & $\mathrm{MW}$ \\
\hline Generator Pulse Duration & 0.6 & $\mathrm{~S}$ \\
\hline Exciter Losses @ No Load & 11.9 & $\mathrm{~kW}$ \\
\hline Exciter Losses @ Full Load & 63.0 & $\mathrm{~kW}$ \\
\hline Hydraulic Motoring Pressure & $44.8 \times 10^{3}$ & $\mathrm{kPa}$ \\
\hline Hydraulic Retum Pressure & $2.24 \times 10^{3}$ & $\mathrm{kPa}$ \\
\hline
\end{tabular}

Figure 3 is a graph of the hydrodynamic bearing friction and rotor windage loss curves as a funcrion of generator speed, which are used in calculating the power available for accelerating the rotor. Figure 4 shows the simulation output of generator speed versus time for a typical $10 \mathrm{MW}, 600 \mathrm{~ms}$ discharge. The hydraulic system takes just over seven minutes to initially reach $3600 \mathrm{rpm}$ and approximately $80 \mathrm{~s}$ to remotor after this discharge pulse.

The simulation is divided into seven discrete sections to cover the various operating modes of the hydraulic system. The first section covers operation from rest to $500 \mathrm{rm}$. In this speed range, the generator rotor is supported on hydrostatic lift bearings, and bearing friction and windage losses are negligible. The simulation calculates the hydraulic motor output torque and rotor acceleration and generates the rotor speed change during each time step. When rotor speed reaches $500 \mathrm{rpm}$, the program switches to the second section. 


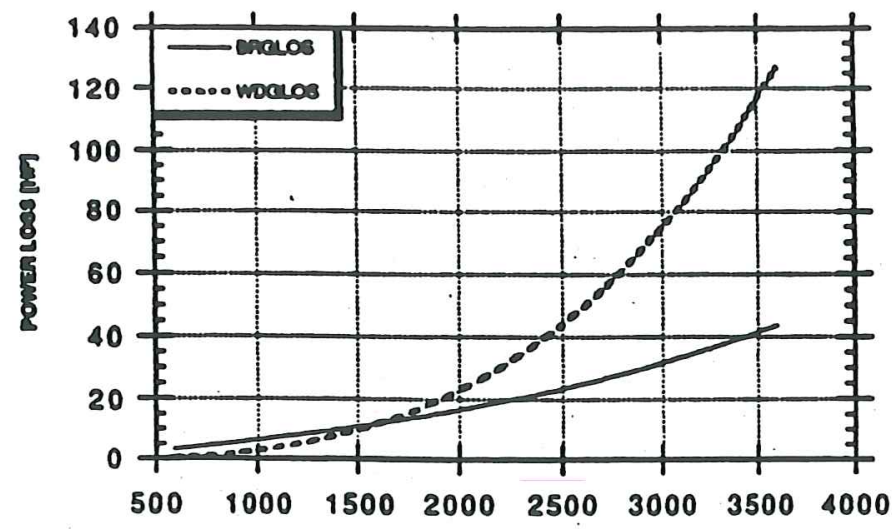

AБMERATOด SQPBO (APU)

Figure 3. Simulation output -- generaror losses vs. speed

In this secrion, the output of the hydraulic system increases until the input power to the electric motor reaches the $298 \mathrm{~kW}$ limit Generator bearing friction and windage losses are calculated as a function of rotor speed. The rotor windage losses are calculated using a third order polynomial curve fit equation generated from empirical data provided by Westinghouse. The generator bearing losses are also calculated using a third order polynomial curve fit equation based on computer simulation data provided by Orion Corporation, the supplier of the hydrodynamic bearings. The simulation calculares the output power of the hydraulic motor based on a hydraulic motor efficiency factor generated as a function of system pressure and flowrate. The system also uses a calculated pump efriciency and the flow losses in the system to calculate the power input required by the main hydraulic pump. Finally, the electric motor efficiency is considered to calculate the power pulled from the utility grid. The power required to of fset bearing friction and windage losses is subtracted from the hydraulic motor output and the balance is used to calculate the incremental change in rotor stored energy and speed during the time step. This section of the simulation is used until the hydraulic pump reaches maximum displacement and the elecric motor input power reaches $298 \mathrm{~kW}$.

In the third section of the simulation, the rotor is accelerated to the maximum operating speed interactively selected by the operator. In this section, the system power level remains constant and the ourput torque of the hydraulic motor decreases linearly with increasing rotor speed. These calculations simulate the reduction in hydraulic motor displacement and the corresponding decrease in motor output rorque.

Once the rotor reaches maximum speed and is no longes being accelerated, the hydraulic system power level drops to match the generator friccion and windage losses. System flowrate remains constant (generator speed is unchanged) but the system pressure falls. This section simulates a hold condition to allow for final system checks prior to discharge.

In the next section, the generator field excitation sequence is iniriated. If the shaft driven exciter has been selected by the operator, the energy for field excikation is taken from the rotor stored energy. This section of the simulation also incorporates the iron losses in the generator during field excitation. In response to the

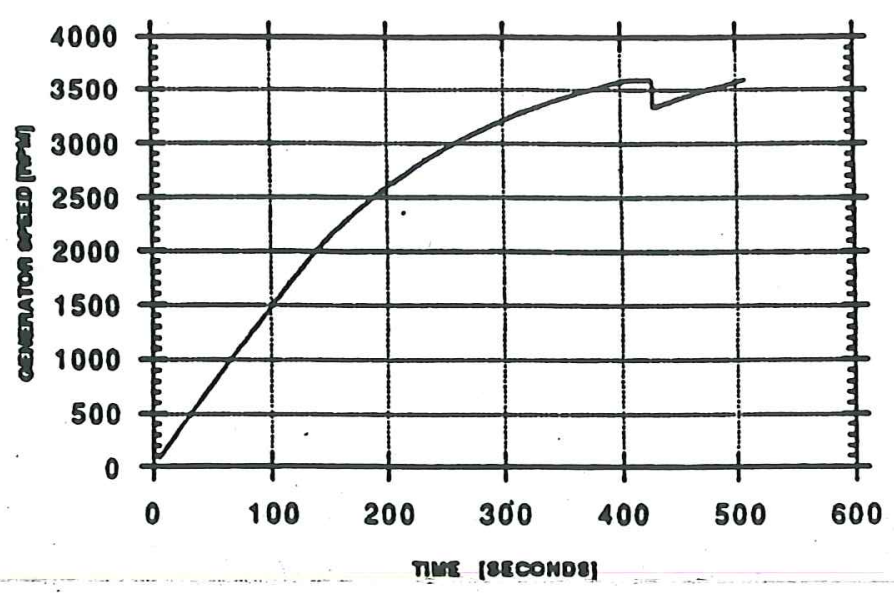

Figure 4. Simulation ou甲ur - generator speed vs. time

,

increased load, the hydraulic system pressure increases until full rated power is reached. The generator remains fully excited for several seconds prior to the discharge pulse to allow for voltage stabilizacion.

After voltage stabilization, the generator discharge pulse is initiated. Because of the relatively low power and slow time constant of the motoring system, the discharge pulse is treated as step load at the power level and duration selected by the operator. The discharge load greatly exceeds the power capability of the motoring system and the generator speed droops significantly.

In the next section of the simulation, the excitation loading is removed from the system and the generator is remotored to full speed. The pressure compensation system auromatically destrokes the main hydraulic pump, reducing the output flowrate while maintaining full system pressure and motor output torque. Pump displacement slowly increases to maximum as the generator is reaccelerated to $3600 \mathrm{pm}$. During this secrion, the ourput power of the hydraulic system drops slightly, but the required remotoring time should not be exceeded. After the generator has renurned to 3600 $\mathrm{rpm}$, the system is ready to repeat the excitation and discharge sequence.

\section{Acknowledgement}

The work described in this paper was performed under DOE Grant number DE.FG05-88ER53267.

\section{References}

[1] D. Terry, et al., "Overview of Texi Power System Upgrade," IEEE Proceedings of the Fourteenth Symposium on Fusion Engineering, San Diego, Califomia, September 28 through Ociober 3, 1991.

[2] D. Foster, et al., "Motor-Generators for the TEXT Upgrade Power Supplies," IEEE Proceedings of the Thirleensh Symposium on Fusion Engineering, Knoxville. Tennessee, October 1989. 